\title{
Protein Tyrosine Phosphatase Assays
}

\author{
Ulrike Lorenz \\ The Beirne Carter Center for Immunology Research and Department of Microbiology University of \\ Virginia, Charlottesville, VA 22908
}

\section{Abstract}

Tyrosine phosphorylation and dephosphorylation of proteins play a critical role during many processes of the immune system, from early development to fully differentiated effector function. Since the opposing actions of protein tyrosine kinases (PTKs) and protein tyrosine phosphatases (PTPs) determine the steady state level of tyrosine phosphorylation on a given protein, it is often important for mechanistic studies to determine the specific activities of PTKs and PTPs. PTPs are defined by their enzymatic activity that catalyzes the dephosphorylation of phosphotyrosine residues. This unit focuses on methods to determine the enzymatic activity of PTPs. While there are many varieties of PTP assays, the focus in this unit is on immune complex PTP assays, which do not require elaborate biochemical purifications and are commonly used to test the activities of specific PTPs in the immune system. Although it has become increasingly recognized that PTPs show substrate specificities, most in vitro PTP assay are based on the use of generic surrogate substrates. In the basic protocol provided in this unit, dephosphorylation of the chromogenic substrate p-Nitrophenyl Phosphate (pNPP) is measured to determine the enzymatic activity of the PTP. In the first alternative protocol, the release of inorganic phosphate from a phosphopeptide is quantified using the Malachite Green Assay. The second alternative protocol uses a radioactivelylabeled phosphoprotein as substrate, and the amount of released radioactivity is used to assess PTP activity.

\section{Keywords}

protein tyrosine phosphatase; protein tyrosine phosphatase assay; immunoprecipitations; pNPP; phosphoprotein; phosphopeptide; Malachite Green Assay; radioactively-labeled phosphoproteins

\section{Protein Tyrosine Phosphatase Assays}

Tyrosine phosphorylation and dephosphorylation of proteins play a critical role during many processes of the immune system, from early development to fully differentiated effector function [reviewed in (Hermiston et al., 2003; Pao et al., 2007)]. Since the opposing actions of protein tyrosine kinases (PTKs) and protein tyrosine phosphatases (PTPs) determine the steady state level of tyrosine phosphorylation on a given protein, it is often important for mechanistic studies to determine the specific activities of PTKs and PTPs. Unit 11.4 in this chapter addresses assays to measure kinase activities of PTKs. This Protein Tyrosine Phosphatase assay unit focuses on methods to determine the enzymatic activity of PTPs. Any of the protocols in this unit can be used to measure the PTP activity of primary cells as well as of immortalized cell lines grown in culture, and can be combined with protocols of cell activation as needed. While there are many varieties of PTP assays, Basic Protocol 1 describes an immune complex PTP assay that is commonly used to test the activities of

Address: University of Virginia Health System, Beirne Carter Center for Immunology Research, P.O. Box 801386, Charlottesville, VA 22908-1386, Phone: (434) 243 2623, FAX: (434) 924 1221, ulorenz@ virginia.edu. 
specific PTPs in the immune system. While the immune complex PTP assay requires the availability of a specific antibody recognizing the PTPs of interest, it has the advantage of providing a relatively easy way to measure the activity of a particular PTP without extensive biochemical purification. However, it is important to realize that the binding of antibodies to the PTP can cause conformational changes of the PTP and can therefore potentially alter the specific activity of the PTP. Alternatively, the protocol assaying PTP activity can be modified to assess the overall PTP activity of whole cell lysates or subcellular fractions (Basic Protocol 2). In that setting, the immunoprecipitation will have to be substituted with cell lysis followed by cell fractionation. However, there are several issues that need to taken into consideration, such as that the lysis/fractionation buffer should be phosphate-free and compatible with PTP assays. If that is not an option, the use of spin columns can be included in the protocol, which presents a method to change the buffer composition and remove small molecules. Additional precautions are necessary depending on the particular PTP assay employed. For example, if the release of inorganic phosphate will be used to measure PTP activity, the sample itself cannot contain free phosphate. Alternate Protocol 1 describes a phosphatase assay that uses phosphoprotein as substrate followed by the Malachite Green Assay. Finally, Alternate Protocol 2 describes a phosphatase assay that uses radioactivelylabeled phosphoprotein as substrate.

\section{Basic Protocol 1 \\ Immune Complex Assays for Protein Tyrosine Phosphatases}

The first section of this protocol describes the isolation of the PTP via immunoprecipitation, which can then be combined with any of the three PTP assays listed afterwards. The immunoprecipitation can be omitted if the PTP will be purified via biochemical procedures or if whole cell lysates or fractions are to be assessed for PTP activity. In those cases, one can go straight to the PTP assay. Before performing the immunoprecipitation to purify the PTP activity, the following criteria are important to consider when choosing the right antibody: the ideal antibody is highly specific to minimize non-specific precipitation of other phosphatase activities, it binds to a site of the PTP that does not interfere with its activity, and it can be added at a concentration that precipitates 'all' of the available PTP (loosely referred to as 'clearing antibody') to allow for quantification of PTP activity and comparison between different samples.

The number of cells that need to be lysed per data point depends on the abundance and activity of the specific phosphatase that is assayed. While $5 \times 10^{6}-5 \times 10^{7}$ cells should provide a reasonable range to achieve measurable phosphatase activity for most of commonly tested PTPs of the immune system, it is recommended that the optimal number of cells be experimentally determined for each phosphatase and cell type. As a general rule, the amount of assayed phosphatase and the assay time should allow measurement of the enzymatic activity in the linear range, i.e. where there is a direct correlation between the amount of protein and the enzymatic activity. This would allow calculating the specific activity of the enzyme.

\section{Materials}

Cells of desired type

Phosphate-Buffered Saline (PBS, Appendix 2A), ice cold

$5 \times$ NP 40 lysis

$1 \times$ NP 40 lysis buffer (freshly supplemented with protease inhibitors), ice-cold

Antibodies against protein of interest (polyclonal or monoclonal) 
Protein A- or Protein G-Sepharose (GE Healthcare)

$1 \times$ Phosphatase buffer

Phosphatase substrate; p-Nitrophenyl Phosphate (pNPP)

$\mathrm{NaOH}[1 \mathrm{~N}]$

\section{Procedure}

\section{Harvest and Lyse Cells}

1 Prepare $5 \times 10^{6}-5 \times 10^{7}$ cells, either freshly harvested or following stimulation of choice

- When using suspension cells, such as lymphocytes, pellet cells via centrifugation $5 \mathrm{~min}$ at $\sim 500 \mathrm{~g}$ ). when using adherent cells, such as macrophages, use a cell scraper to detach cells and collect them into ice-cold PBS before pelleting via centrifugation at $4^{\circ} \mathrm{C}$

2 Resuspend cell pellet in $1 \mathrm{ml}$ ice-cold PBS

3 Transfer resuspended cells into $1.5 \mathrm{ml}$ microcentrifuge tube

4 Centrifuge for $5 \mathrm{~min}$. at $\sim 500 \mathrm{~g}$ at $4^{\circ} \mathrm{C}$

$5 \quad$ Fully resuspend and lyse cell pellet in $500 \mu 1$ ice-cold NP 40 lysis buffer (freshly supplemented with protease inhibitors; this is critical to preserve proteins in an intact form) using Vortex and/or pipette

6 Gently rock on Nutator for $30 \mathrm{~min}$ at $4^{\circ} \mathrm{C}$

$7 \quad$ Centrifuge lysed cells for $30 \mathrm{~min}$. at $>20,000 \mathrm{~g}$ at $4^{\circ} \mathrm{C}$.

This will pellet DNA and small non-soluble particles, which would otherwise cause contamination of Immunoprecipitation.

8 Transfer supernatants to new microcentrifuge tubes.

\section{Immunoprecipitate PTP}

Note that Chapter 8, Section 2 describes in detail several alternative methods for immunoprecipitation; the following method is one example that works well in combination with PTP

$9 \quad$ Add antibodies of choice to clarified cell lysates.

In order to get a quantitative result from the PTP assay, it is critical that the added amount of antibody fully 'clears' or precipitates in entirety the protein of interest from the cell lysates. The required amount of antibody will initially have to be experimentally determined for each antibody/cell type/cell number configuration

10 Incubate on Nutator for $1 \mathrm{hr}$ - overnight at $4^{\circ} \mathrm{C}$

The o.n. incubation should only be considered if it is known that the PTP activity is stable for that length of time

\section{Prepare Protein A- or Protein G-Sepharose Beads}

11 Pellet beads by brief centrifugation in microcentrifuge (30 sec - $1 \mathrm{~min}$ at high speed). Wash beads $3 \times$ in NP 40 lysis buffer ( $1 \mathrm{ml}$ each) and resuspend in 1 vol. NP 40 lysis buffer. 
It is advisable to use $15 \mu$ l of packed beads/Immunoprecipitation. This will provide an easily detectable pellet following centrifugation. Beads should always be resuspended by gently turning the tubes by hand and NEVER be vortexed.

12 Add $30 \mu \mathrm{l}$ Protein A- or Protein G-Sepharose beads (50\% v/v)

13 Incubate on Nutator for $45 \mathrm{~min}-1 \mathrm{hr}$ at $4^{\circ} \mathrm{C}$

14 Wash immunoprecipitates 3 times with NP 40 lysis buffer

(1 $\mathrm{ml}$ each, spin down for $30 \mathrm{sec}-1 \mathrm{~min}$ at high speed in microcentrifuge)

15 Wash immunoprecipitates $2 \times$ with phosphatase buffer

( $1 \mathrm{ml}$ each, spin down for $30 \mathrm{sec}-1 \mathrm{~min}$ at high speed in microcentrifuge)

16 Transfer resuspended beads into new microcentrifuge tube before last centrifugation.

This will further reduce contamination that results from non-specific sticking to microcentrifuge tubes.

17 Resuspend beads in 40-100 $\mu$ l phosphatase buffer depending on assay, keep on ice until initiation of the phosphatase assay of choice (see Basic Protocol 1 and alternate Protocols 1 and 2).

\section{Basic Protocol 2}

\section{Phosphatase assay Using of pNPP as substrate}

PTPs are defined by their enzymatic activity that catalyzes the dephosphorylation of phosphotyrosine residues. Although it has become increasingly recognized that PTPs show substrate specificities [reviewed in (Tiganis and Bennett, 2007)], most in vitro PTP assay are based on the use of generic surrogate substrates. Moreover, it has proven difficult to reproduce in vitro any in vivo substrate selectivity, which in many cases is due to noncatalytic domains of the PTPs causing accumulation of the PTP to restricted subcellular localization in proximity to specific substrates and/or help the binding of substrates.

In this protocol, we describe one of the most commonly used PTP assays that employs the use of p-Nitrophenyl Phosphate (pNPP) as a non-proteinaceous and non-specific substrate measurement of released p-nitrophenyl to assay PTP activity. The use of pNPP is the easiest and cheapest method, but also the least selective. Phosphopeptides or -proteins are slightly more physiological substrates than pNPP since they are protein-based, but such peptides are still generic substitutes and in general not related to the natural in vivo substrates. Two other common methods are described in Alternate Protocols 1 and 2 in which different substrates and methods are used for detection of phosphatase activity. Both alternative methods, which use phosphopeptides or -proteins as substrates, are based on the same principle of measuring the release of free phosphate, but they differ in the method of detection. In the Malachite Green Assay (Alternate Protocol 1), the amount of released inorganic phosphate is determined by measuring the absorbance of a molybdate:malachite green:phosphate complex (Van Veldhoven and Mannaerts, 1987). In contrast, the 'radioactive' PTP assay (Alternate Protocol 2) uses a substrate where a radioactive isotype of phosphorus $\left({ }^{32} \mathrm{P}\right.$ or ${ }^{33} \mathrm{P}$ ) is incorporated in the phosphate moiety of phosphotyrosines. The amount of hydrolyzed phosphate is determined by measuring the released radioactivity. When choosing between the colorimetric versus the radioactive method of detection, the following parameters should be considered. A colorimetric detection is not as sensitive as measurement of radioactivity, but it is less expensive. Moreover, this avoids the practical and regulatory considerations associated with the use of radioactivity. In addition due to 
their decay, radioactive substrates cannot be stored over long times and have to be prepared on a regular basis.

Materials

p-Nitrophenyl Phosphate (pNPP)

Phosphatase buffer

$1 \mathrm{~N} \mathrm{NaOH}$

Spectrophotometer

Add $10 \mu \mathrm{l}$ pNPP ( $250 \mathrm{mM}$ in $1 \times$ phosphatase buffer) to $40 \mu \mathrm{l}$ immunoprecipitated protein

(transferred to new microcentrifuge tube)

Incubate at $30^{\circ} \mathrm{C}$ for various times.

Measurements at 5-10 min intervals over one hour should provide sufficient data to generate a graph that allows identification of the linear range of enzymatic reaction. Samples should be gently mixed every 5-10 min, since beads tend to settle down. For the planning of the experiment, it is important to realize that each data point requires a separate immunoprecipitation. To generate multiple data points from the same cellular source, immunoprecipitation can be scaled up and divided into aliquots just before PTP assay. Alternatively, instead of using numerous time points, serial dilutions of the PTP/immunoprecipitates can be assayed to determine the linear range. In this case, the initial immunoprecipitate will be resuspended in $80 \mu \mathrm{l}$, of which $40 \mu \mathrm{l}$ will be assayed for PTP activity and the remaining $40 \mu \mathrm{l}$ being used for serial dilution, which will be set-up in the same manner.

Stop reaction by adding $1 \mathrm{ml}$ of $1 \mathrm{~N} \mathrm{NaOH}$

Dephosphorylation of the chromogenic substrate pNPP generates p-nitrophenol, which at an alkaline $\mathrm{pH}$ has an intense yellow color that can be measured at $405 \mathrm{~nm}$ using a spectrophotometer.

Read absorbance at $405 \mathrm{~nm}$

Calculate enzyme activity from the data that fall in the linear range

Enzyme activity $[\mu \mathrm{moles} / \mathrm{min} \mu \mathrm{g}]=50[\mathrm{vol}] \times$ OD $405 \mathrm{~nm} \times 1 /$ time $[\mathrm{min}] \times$ enzyme $[\mu \mathrm{g}] \times 1 / 18,000$ [molar extinction coefficient]

One unit of the PTP activity is defined as the enzyme activity that hydrolyzes 1 $\mathrm{nmol}$ of pNPP in $1 \mathrm{~min}$ at $30^{\circ} \mathrm{C}$ in a reaction volume of $50 \mu 1$.

\section{Alternate Protocol 1}

\section{Phosphatase assay using phosphoprotein as substrate followed by the Malachite Green Assay}

This colorimetric method is based on the reaction of phosphomolybdate with malachite green, which leads to the formation of a colored complex (Carter and Karl, 1982). A range of commonly used phosphopeptides is commercially available (Promega, Madison, WI) or can be chemically synthesized according to specific needs.

\section{Materials}

Phosphopeptides, can be chemically synthesized to order or alternatively some more commonly used peptides are commercially available, such as those peptides provided as part of the Tyrosine Phosphatase Assay System from Promega 
Phosphate Standard $\left(100 \mu \mathrm{M} \mathrm{KH}{ }_{2} \mathrm{PO}_{4}\right)$

Solution A (molybdate)

Solution B (malachite green)

Solution C (7.8\% (v/v) $\left.\mathrm{H}_{2} \mathrm{SO}_{4}\right)$

Since this assay is based on measuring released inorganic phosphate, it is critical that none of the samples or any of the buffers used throughout the assays contain free phosphate or are phosphate-based.

The assay can be performed in microcentrifuge tubes or a 96 well plate depending on the abundance of the assayed PTP and/or availability of a plate reader, which can measure absorbance at 600 or $630 \mathrm{~nm}$.

Malachite green is toxic and a powerful dye, and therefore it may be worthwhile to consider using a commercially available kit instead of preparing all the reagents in the laboratory. Phosphate detection kits are offered by a number of manufacturers and are based on the molybdate-malachite green complex formation. The decision will depend on how routinely the assays will be used, which will determine the cost efficiency versus effort involved.

The following protocol is designed to be performed in microcentrifuge tubes, but can be easily scaled down to a 96 well plate using a reaction volume of 50-100 $\mu 1$.

A dilution of the phosphate standard needs to be prepared before assaying of the PTPs, since the standard curve has to be measured in parallel with the enzyme assay.

It is recommended to use disposable cuvettes for reading the absorbance at the end of the assay, since Malachite Green is a strong dye that it difficult to clean from cuvettes.

\section{Preparation of phosphate standards}

Dilute $100 \mu \mathrm{l}$ phosphate $[100 \mu \mathrm{M}]$ in $900 \mu 11 \times$ phosphatase buffer (1:10 dilution)

Take $500 \mu 1$ and add to $500 \mu 11 \times$ phosphatase buffer (1:2 dilution); use remaining $500 \mu 1$ for standard curve

Repeat serial 1:2 dilution until concentration is $0.19 \mu \mathrm{M}$

This will have generated the following phosphate standards:

$0.19,0.39,0.78,1.56,3.12,6.25,12.5,25,50$, and $100 \mu \mathrm{M}$ phosphate, it is important to also include a blank point, that only contains $1 \times$ phosphatase buffer

Pipette $350 \mu 1$ of phosphate standards into disposable cuvettes, which will be treated in parallel with PTP samples

\section{PTP assay using phosphopeptides as substrate}

Phosphopeptide concentration should be between 10-100 $\mu \mathrm{M}$

Transfer immunoprecipitated protein (resuspended in $100 \mu 11 \times$ phosphatase buffer) to microcentrifuge tube

Add $1 \times$ phosphatase buffer so that final volume, including phosphopeptide, is $400 \mu 1$

Add phosphopeptide to start the reaction 
Incubate at $30^{\circ} \mathrm{C}$ for various times.

As described in detail above in the basic protocol, measurements taken at 5-10 min intervals over one hour should provide sufficient data to generate a graph that allows identification of the linear range of enzymatic reaction. Alternatively, instead of using numerous time points, serial dilutions of the PTP/ immunoprecipitates can be assayed to determine the linear range. In this case, the initial immunoprecipitate will be resuspended in $200 \mu \mathrm{l}$, of which $100 \mu \mathrm{l}$ will be assayed for PTP activity and the remaining $100 \mu \mathrm{l}$ being used for serial dilution, which will be set-up in the same manner.

Briefly spin down and transfer $350 \mu 1$ of supernatant into cuvette

\section{Detection of released inorganic phosphate}

Start including phosphate standards from this point onward

Stop reaction by adding $245 \mu$ l solution A (molybdate)

Add $105 \mu$ l solution B (malachite green), mix

Incubate 5-10 min at room temperature

Add $700 \mu$ solution $\mathrm{C}\left(\mathrm{H}_{2} \mathrm{SO}_{4}\right)$, mix

Incubate for $1 \mathrm{hr}$ at room temperature

Measure absorbance at $620 \mathrm{~nm}$

\section{Alternate Protocol 2}

\section{Phosphatase assay using radioactively-labeled phosphoprotein as substrate}

The use of radioactively labeled substrates, which have a radioactive isotype (32P or 33P) incorporated into the phosphate moieties of their phosphotyrosines, is the most sensitive method and allows for an exact quantitation over a wide range of PTP activities. Similar to the previous protocol, phosphoproteins or phosphopeptides are used as substrates, which are in general non-specific for the PTP to be assayed. However with radioactively labeled substrates, released radioactivity instead of inorganic phosphate is measured to calculate PTP activities. While this provides a higher level of assay sensitivity, it is also the most expensive and labor-intensive method. The substrate has to be freshly prepared by the investigator and because of the radioactive decay it can only be stored for a few weeks. In addition, the use of radioactivity requires numerous precautions and regulatory measures. The protective procedures that have to be in place and have to be followed to ensure the safety of the investigator and environment are not described here, since they are standard for radioactive usage and not specific for this PTP assay.

\section{Materials}

Myelin Basic Protein (MBP)

Abl Protein Kinase

$\gamma$-ATP (3000Ci/mmol)

Abl kinase buffer 
$\mathrm{MnCl}_{2}$

$\mathrm{Na}_{3} \mathrm{VO}_{4}$

Bovine Serum Albumin (BSA)

Trichloroacetic acid (TCA)

Scintillation cocktail and Scintillation counter

Preparation of radioactively-labeled phosphoproteins-Radioactively labeled substrates are prepared via peptide or protein phosphorylation by a protein kinase, such as $\mathrm{Src}$ or Abl, in the presence of $\left[\gamma_{-}{ }^{32} \mathrm{P}\right] \mathrm{ATP}$. Following incubation of these substrates with the PTP, release of ${ }^{32} \mathrm{P}_{\mathrm{i}}$ is measured to determine phosphatase activity.

\section{Preparation of ${ }^{32}$ P-Tyrosine Myelin Basic Protein (MBP)-}

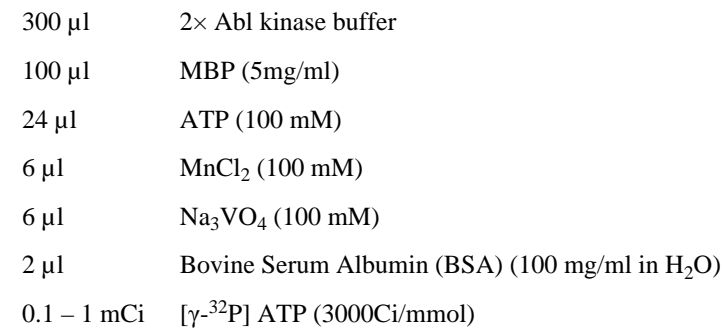

The amount of added $\gamma$-ATP depends on the individual need to generate substrates of higher or lower specific activity. A higher specific activity of the substrate will allow the detection of lower phosphatase activity.

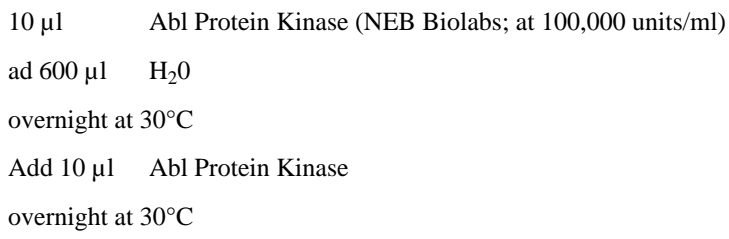

- $\quad$ Take $5 \mu 1$ sample to measure total input radioactivity and calculate specific activity of ATP, dilute $1: 100$ with $\mathrm{H}_{2} \mathrm{O}$ and count three $10 \mu \mathrm{l}$ aliquots

specific activity $[\mathrm{cpm} / \mathrm{pmol}]=[$ measured counts $] \times 1 / 10$ [aliquot size $] \times 100$ [dilution] $\times 610$ [reaction volume] $\times 1 / 2400,000$ [total pmol of ATP]

Precipitation of 32P-labeled MBP-Add Trichloroacetic acid to achieve $15 \%$ final concentration $(110 \mu \mathrm{l}$ of $100 \% \mathrm{TCA})$

15 min. on ice

Centrifuge at $>15,000 \mathrm{~g}$ for $10 \mathrm{~min}$ at $4^{\circ} \mathrm{C}$

Wash pellet two times with $15 \%$ TCA:

vortex pellet with $1 \mathrm{ml} 15 \%$ TCA followed by 5 min centrifugation at $4{ }^{\circ} \mathrm{C}$

Wash pellet two times with ice-cold acetone:

vortex pellet with $1 \mathrm{ml}$ acetone followed by 5 min centrifugation at $4^{\circ} \mathrm{C}$

Let pellet air dry 
Resuspend pellet in $210 \mu 11 \times$ phosphatase buffer, incubate at $37^{\circ} \mathrm{C}$ until dissolved

- $\quad$ Take and count two $5 \mu 1$ samples to measure incorporated radioactivity and calculate incorporated phosphate concentration

Phosphate concentration $[\mu \mathrm{M}]=[$ measured counts $] /$ specific activity $\times 1 / 5$ [sample vol.]

${ }^{32} \mathrm{P}-$ Tyrosine-labeled MBP can be diluted in $1 \times$ substrate buffer to a final concentration of $25 \mu \mathrm{M}$ phosphotyrosine and be stored at $4^{\circ} \mathrm{C}$ for up to a month.

Use of ${ }^{32} \mathrm{P}$-labeled phosphoproteins as substrate-Transfer $40 \mu \mathrm{l}$ of immunoprecipitated protein (resuspended in $1 \times$ phosphatase buffer) to microcentrifuge tube

Since this method is very sensitive, it is critical to incorporate controls for unspecific dephosphorylation, such as phosphatase buffer and Sepharose beads by themselves, or control immunoprecipitations with unrelated antibody.

Add $10 \mu 1$ of ${ }^{32} \mathrm{P}$-labeled MBP $(25 \mu \mathrm{M}$ phosphotyrosines $)$

Incubate at $30^{\circ} \mathrm{C}$ for various times.

As described in detail above in the basic protocol, measurements taken at 5-10 min intervals over one hour should provide sufficient data to generate a graph that allows identification of the linear range of enzymatic reaction. Alternatively, instead of using numerous time points, serial dilutions of the PTP/ immunoprecipitates can be assayed to determine the linear range. In this case, the initial immunoprecipitate will be resuspended in $80 \mu \mathrm{l}$, of which $40 \mu \mathrm{l}$ will be assayed for PTP activity and the remaining $40 \mu \mathrm{l}$ being used for serial dilution, which will be set-up in the same manner.

Stop reaction by adding $200 \mu 1$ ice-cold TCA (20\%), vortex

Incubate on ice for $10 \mathrm{~min}$.

Centrifuge at $>15,000 \mathrm{~g}$ for $10 \mathrm{~min}$ at $4^{\circ} \mathrm{C}$

Take $200 \mu$ l of supernatant and measure released radioactivity in scintillation counter, and in parallel measure input radioactivity by directly counting $10 \mu 1$ of ${ }^{32} \mathrm{P}$-labeled MBP.

\section{Calculate activity of sample-}

Released cpm = sample cpm - blank cpm [derived from control sample]

Activity $($ unit $/ \mathrm{ml})=$ released $\mathrm{cpm} /($ total $\mathrm{cpm}-$ blank cpm $) \times 0.25[\mathrm{nmol}$ phosphotyrosine] $\times 1 / \mathrm{min}$ [reaction time] $\times 250 / 200$ [correction for measured vs. total sample] $\times 20$ [convert to $1 \mathrm{ml}$ instead of $50 \mu \mathrm{l}]$

One unit of the PTP activity is defined as the enzyme activity that hydrolyzes 1 nmol phosphate from tyrosine phosphorylated MBP [ $5 \mu \mathrm{M}$ phosphotyrosines] in 1 min at $30^{\circ} \mathrm{C}$ in a reaction volume of $50 \mu 1$.

If the concentration of the PTP is known, the overall activity can be converted in specific enzyme activity (units/mg). 


\section{Reagents and Solutions}

\section{5× NP-40 lysis buffer}

- $5 \%$ Nonidet P40 or the now available Nonidet P40 Substitute (USB/Affymetrix), do not confuse with NP-40, which is a Polyglycol ether surfactant

- $\quad 750 \mathrm{mM} \mathrm{NaCl}$

- $250 \mathrm{mM}$ Tris- $\mathrm{HCl}(\mathrm{pH} 8.0)$

\section{Protease inhibitors, stock solutions}

- Antipain $(1 \mathrm{mg} / \mathrm{ml} ; 1000 \times) 1 \mu \mathrm{g} / \mathrm{ml}$ final

- Aprotinin $(10 \mathrm{mg} / \mathrm{ml} ; 10.000 \times) 1 \mu \mathrm{g} / \mathrm{ml}$ final

- Leupeptin $(10 \mathrm{mg} / \mathrm{ml} ; 1000 \times) 10 \mu \mathrm{g} / \mathrm{ml}$ final

- Pepstatin A (1mg/ml; 1000× $1 \mu \mathrm{g} / \mathrm{ml}$ final

- $\quad \operatorname{PMSF}(10 \mathrm{mg} / \mathrm{ml} ; 500 \times) 20 \mu \mathrm{g} / \mathrm{ml}$ final

\section{$2 \times$ Abl kinase buffer}

- $100 \mathrm{mM}$ Tris- $\mathrm{HCl}(\mathrm{pH} 7.5)$

- $20 \mathrm{mM} \mathrm{MgCl}_{2}$

- 2 mM EGTA

- $0.02 \%$ Brij 35

\section{2x phosphatase buffer}

- $50 \mathrm{mM}$ Hepes ( $\mathrm{pH} 7.4)$

- 0.2 mM EDTA

- $10 \mathrm{mM}$ DTT

- $200 \mu \mathrm{g} / \mathrm{ml} \mathrm{BSA}$

- $0.02 \%$ Brij 35

$500 \mathrm{mM}$ pNPP in $\mathrm{H}_{2} \mathrm{O}$

Phosphate Standard (100 $\left.\mu \mathrm{M} \mathrm{KH}_{2} \mathrm{PO}_{4}\right)$

Solution A (molybdate): $\operatorname{mix} 4$ vol. $2 \mathrm{~N} \mathrm{HCl}$ with 3 vol. $0.1 \mathrm{M} \mathrm{Na}_{2} \mathrm{MoO}_{4}$

Solution B (malachite green): $0.042 \%(\mathrm{w} / \mathrm{v})$ malachite green dye in $1 \%(\mathrm{w} / \mathrm{v})$ polyvinyl alcohol

Solution C (7.8\% (v/v) $\left.\mathbf{H}_{2} \underline{\mathbf{S O}_{4}}\right):$ : $7.8 \%(\mathrm{v} / \mathrm{v}) \mathrm{H}_{2} \mathrm{SO}_{4}$

\section{Commentary}

\section{Background Information}

PTPs are a group of enzymes that are defined by their ability to hydrolyze the phosphate from phosphotyrosines. Based on recent sequencing projects of the human genome, more than 100 putative protein tyrosine phosphatases have identified [reviewed in (Alonso et al., 2004)]. These PTPs can be sorted into 4 groups based on their substrate specificity. The 
largest group, the Cys-based class I PTPs, consists of the so-called 'classical' PTPs, which are true tyrosine-specific PTPs. This group can be further subdivided by their cellular localization into transmembrane (TM) and non-TM families. Additional members of the class I PTPs are the 'dual specificity' PTPs, which recognize phosphoserine and phosphothreonine as substrates besides phosphotyrosine. Class II-IV PTPs are much smaller groups of PTPs; with the following classifications: PTPs that are structurally related to bacterial arsenate reductases are grouped into class II, while class III contains Cys-based PTPs that recognize phosphotyrosines and phosphothreonine, and Asp-based PTPs are grouped in class IV.

One of the best studied PTP of the immune system is CD45, a TM PTP [reviewed in (Holmes, 2006)], which executes its function via dephosphorylation of src-family kinases, thereby directly controlling their activities [reviewed in (Huntington and Tarlinton, 2004)]. Although many non-TM PTPs are well recognized for their critical roles in the development and function of immune cells, their mechanism of action is often less understood and only some of their specific substrates are identified [reviewed in (Pao et al., 2007)].

PTP assays take advantage of the fact that PTPs tend to loose their substrate specificity once they are taken out of the cellular milieu. All of the above-described protocols use surrogate substrates to measure enzymatic activity. However, the alternative protocols can be modified and MBP or the generic phosphopeptide can be substituted with the 'real' substrate. The three listed protocols represent the most commonly used PTP assays, but numerous variations and alternative PTP assays have been developed to accommodate specific needs. For example, an ELISA-based PTP assay based on the antibody-mediated detection of phosphotyrosines has been designed to efficiently screen whole protein fractions following biochemical purifications (Sozio et al., 2004). Alternatively, to determine the molecular weight of a PTP activity in a mixture, in-gel assays have been employed (Markova et al., 2005). In these assay, PTP activity is detected within a renatured SDS-polyacrylamide gel that has radioactive substrates polymerized within the gel. Upon incubation, PTP activity is detected by the selective loss of radioactivity in a band of particular molecular weight. While this assay provides information about the molecular weight and is useful in the identification of unknown PTP activity within a sample, it lacks the quantitative aspect of a PTP assay. For additional background information, variations and alternative approaches, an excellent discussion of tyrosine phosphatase assays can be found in (Montalibet et al., 2005).

All of the above protocols describe discontinuous endpoint assays, where the reaction is stopped following a pre-determined incubation time. Any assay that requires manipulation following the PTP assay to measure the amount of hydrolyzed phosphate can only be designed as a discontinuous assay, and usually various time points are needed to allow a quantitative analysis. However, some colorimetric assays allow quantification of the hydrolyzed product without interference with the sample. For example, hydrolysis of pNPP, which by itself is colorless, generates $p$-nitrophenol, which is bright yellow at an alkaline $\mathrm{pH}$ and whose absorbance can be measured at $405 \mathrm{~nm}$. For PTPs that are active at an alkaline $\mathrm{pH}$, this would be a good choice to continuously measure substrate hydrolysis. However, the majority of PTPs require a lower $\mathrm{pH}$ for their optimal enzymatic activity. For those, DiFMUP (6,8-difluoro-4-methylumbelliferyl phosphate) can be used as an alternative substrate since the fluorescence or absorbance of the hydrolyzed product can be detected over a wide $\mathrm{pH}$ range.

\section{Critical Parameters and Troubleshooting}

It is critical for all of the PTP assays - as it is in general for any assay - to include controls both negative controls to determine non-specific background activity, as well as positive 
controls to confirm that the assay was performed as intended. Controls also provide critical information when troubleshooting potential problems.

Negative controls include the use of control antibodies to ensure that the precipitated activity is specific for the assayed PTP. The inclusion of a data point where instead of the cell lysate only lysis buffer was added to the immune precipitation will measure background activity contributed by buffers, antibodies, and protein $\mathrm{A} / \mathrm{G}$ beads.

Positive controls are helpful when it is necessary to troubleshoot the PTP assay for lack of detectable activity. However, they depend on the availability of PTPs. Several PTPs are commercially available, and while they can be used to generally confirm that the assay works, their activities will not address problems specific for the tested PTP, such as steps of the purification or PTP assay conditions. If the scientist has access to the specific PTP in a purified form, it would provide the ideal positive control, but it is not an absolute requirement.

The conditions used for protocols in this unit are based on what has been beneficial for most of the commonly tested PTPs, but one has to be aware that they will not be the optimal conditions for every PTP, and that specific conditions will have to be empirically determined. One should consider the described conditions as a starting point, which needs to be further defined depending on the need of the studies. If the question asked is one of qualitative nature, such as whether or not the sample contains PTP activity, it is sufficient. But for more quantitative analyses, such as comparison of substrates or inhibitor studies, a range of $\mathrm{pH}$ should be tested. Moreover, it is critical that the substrate is in excess, so that PTP activity can be measured in the linear range of the assay. Similarly, the concentration of the PTP should be high enough to observe detectable hydrolysis in a reasonable time but is still in a linear range with excess substrate.

If only very low activity or no activity is detectable, the amount of input material may need to be increased. The proposed range of $5 \times 10^{6}-5 \times 10^{7}$ cells is based on PTPs that are expressed at levels easily detectable by Western Blot and have displayed measurable enzymatic activity (Kilgore et al., 2003). Using a range of protein concentrations should convey whether too little protein caused the low activity. Alternatively for low activity PTPs, it might be necessary to use the radioactive PTP assay instead of a colorimetric assay. Besides the lack of protein, one has to also consider whether there was a loss of activity during the preparation of the sample. For example, it is critical to freshly include sufficient amounts of protease inhibitors in the cell lysis, exclude PTP inhibitors during every step, and keep the samples on ice or at $4^{\circ} \mathrm{C}$. Alternatively, it is possible that the PTP is inactive at the $\mathrm{pH}$ used during the reaction. While most PTPs have been shown to be active in the $\mathrm{pH}$ range between 5.0 and 7.5, the optimal $\mathrm{pH}$ not only varies between PTPs, but can also change for the same PTP when incubated with different substrates [reviewed in (Zhang, 1998)].

If the background activity is too high, this could be due to contamination of the immunoprecipitations, and additional washes or switching to an antibody with less nonspecific binding may be needed to lower the background activity. Alternatively, buffers and the substrate should be checked to identify the source of the contamination. Potential sources of contamination differ between the various PTP assays. If the release of inorganic phosphate is measured by a colorimetric assay, any contamination with phosphate will produce a high background, whereas in the case of the pNPP assay, high background is usually caused by contamination with non-specific PTPs in the assay. The radioactive PTP assay is the most sensitive one, and a not fully precipitated substrate or an accidental contact of the pipette with the non-hydrolyzed substrate pellet can lead to a high background. 
In order to calculate the specific activity of the PTP, the protein amount needs to be determined. This can be achieved by quantitative Western Blotting (Gallagher, 2001), which includes controls of predetermined protein concentrations, or by direct protein staining after SDS-polyacrylamide electrophoresis (Echan and Speicher, 2002). To determine the Michaelis-Menten constant $\left(\mathrm{K}_{\mathrm{M}}\right)$ and the turnover number $\left(\mathrm{k}_{\mathrm{cat}}\right)$, the above described protocols need to be modified so that a constant amount of protein will be tested against varying amounts of substrate. For more sophisticated enzyme kinetics, it is recommended to consult the specialized literature (Segel, 1976).

\section{Anticipated Results}

For the pNPP assay and the Malachite Green Assay, absorbance should be in the range of 0.05 and 1 to get the most interpretable results. The background should be $<0.02$.

For the radioactive substrate assay, it is expected that the incorporated radioactivity of a freshly prepared substrate be between $10^{5}-10^{6} \mathrm{cpm} /$ data point. The background should be $<2,000 \mathrm{cpm}$, and the released phosphate should be $<30 \%$ of input cpm.

\section{Time Consideration}

The immunoprecipitation procedure usually takes 3-4 hours, which includes 1 hour for the initial cell lysis. Should the cells need to be activated before harvesting, additional time will be required.

The exact time for the PTP assays varies depending on the length of the incubation. Assuming the incubation is $\leq 1$ hour: the pNPP assay takes 1-2 hours, the Malachite Green Assay (including the preparation of the standard curve) about 3 hours and the radioactive assay $1.5-2.5$ hours.

The preparation of the substrate takes $30 \mathrm{~min}$. for the initial set-up; $1.5-2$ days for labeling and 3 hours for the final preparation.

\section{References}

Alonso A, Sasin J, Bottini N, Friedberg I, Osterman A, Godzik A, Hunter T, Dixon J, Mustelin T. Protein tyrosine phosphatases in the human genome. Cell. 2004; 117(6):699-711. [PubMed: 15186772]

Carter SG, Karl DW. Inorganic phosphate assay with malachite green: an improvement and evaluation. J Biochem Biophys Methods. 1982; 7(1):7-13. [PubMed: 7153458]

Echan LA, Speicher DW. Protein detection in gels using fixation. Curr Protoc Protein Sci. 2002 Chapter 10: Unit 105.

Gallagher S. Immunoblot detection. Curr Protoc Protein Sci. 2001 Chapter 10: Unit 1010.

Hermiston ML, Xu Z, Weiss A. CD45: a critical regulator of signaling thresholds in immune cells. Annu Rev Immunol. 2003; 21:107-137. [PubMed: 12414720]

Holmes N. CD45: all is not yet crystal clear. Immunology. 2006; 117(2):145-155. [PubMed: 16423050]

Huntington ND, Tarlinton DM. CD45: direct and indirect government of immune regulation. Immunol Lett. 2004; 94(3):167-174. [PubMed: 15275963]

Kilgore NE, Carter JD, Lorenz U, Evavold BD. Cutting edge: dependence of TCR antagonism on Src homology 2 domain-containing protein tyrosine phosphatase activity. J Immunol. 2003; 170(10): 4891-4895. [PubMed: 12734331]

Markova B, Gulati P, Herrlich PA, Bohmer FD. Investigation of protein-tyrosine phosphatases by ingel assays. Methods. 2005; 35(1):22-27. [PubMed: 15588982]

Montalibet J, Skorey KI, Kennedy BP. Protein tyrosine phosphatase: enzymatic assays. Methods. 2005; 35(1):2-8. [PubMed: 15588980] 
Pao LI, Badour K, Siminovitch KA, Neel BG. Nonreceptor protein-tyrosine phosphatases in immune cell signaling. Annu Rev Immunol. 2007; 25:473-523. [PubMed: 17291189]

Segel, IH. Biochemical Calculations: How to Solve Mathematical Problems in General Biochemistry. New York: John Wiley \& Sons; 1976.

Sozio MS, Mathis MA, Young JA, Walchli S, Pitcher LA, Wrage PC, Bartok B, Campbell A, Watts JD, Aebersold R, Hooft van Huijsduijnen R, van Oers NS. PTPH1 is a predominant proteintyrosine phosphatase capable of interacting with and dephosphorylating the T cell receptor zeta subunit. J Biol Chem. 2004; 279(9):7760-7769. [PubMed: 14672952]

Tiganis T, Bennett AM. Protein tyrosine phosphatase function: the substrate perspective. Biochem J. 2007; 402(1):1-15. [PubMed: 17238862]

Van Veldhoven PP, Mannaerts GP. Inorganic and organic phosphate measurements in the nanomolar range. Anal Biochem. 1987; 161(1):45-48. [PubMed: 3578786]

Zhang ZY. Protein-tyrosine phosphatases: biological function, structural characteristics, and mechanism of catalysis. Crit Rev Biochem Mol Biol. 1998; 33(1):1-52. [PubMed: 9543627] 